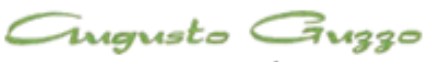

REVISTA ACADEMICA

\title{
Ensino superior: aspectos que envolvem a formação acadêmica
}

\section{na atualidade}

\author{
Simone Aparecida Silva Angelo Bassotto ${ }^{1}$ \\ Recebido em: 12/10/2014. Aprovado em: 24/11/2014. Disponibilizado em: 26/12/2014
}

1. Simone Aparecida Silva Angelo Bassotto é professora de Educação Básica na rede municipal de Guarulhos; Mestre em Educação pela UNICID; Pós-graduada em Docência na Educação Superior pela Pós-Bagozzi; Pós-graduada em MBA- Gestão de Pessoas pela Pós-Bagozzi; Graduada em Pedagogia pela Faculdade Bagozzi; Graduada em Serviço Social pela UNICID; Membro do grupo de pesquisa: Formação e Aprendizagem de profissionais da Educação. Professora no curso de Docência na Educação Superior. Email: simonebassotto@yahoo.com.br.

\section{Resumo}

O presente artigo tem como objetivo versar sobre alguns aspectos que envolvem a formação acadêmica na atualidade, para isso, considerou-se questões sobre a vida adulta na contemporaneidade: desafios constantes, dificuldade para se organizar frente às novas exigências da sociedade e necessidade de enfrentamento de realidades na busca de aperfeiçoamento profissional. A inserção no Ensino Superior, muitas vezes pode ser entendida como modo de ascensão profissional, o que tem aumentado a busca por essa modalidade de ensino, no entanto é importante ressaltar que o acolhimento na Universidade se torna cada vez mais necessário, a fim de que os alunos que se inserem no Ensino Superior superem as dificuldades do processo de inserção, evitando assim, a evasão, o desânimo e promovendo o alcance das aprendizagens significativas.

Palavras-chave: Aprendizagem de adultos; Ensino Superior; Inserção; Acolhimento na Universidade.

\begin{abstract}
This article has the main purpose to manage some aspects that enfold the academic training in the present moment, for this, it was considered issues related to the adult's life in the contemporaneity: constant challenges, difficulties to organize itself in opposite to the new society requirements and the necessity of facing up to the realities of searching professional development. The higher education insertion, can be very often, understood as a way of a professional rising. Which has raised the search for that teaching modality. However it is important to highlight that the welcoming at University becomes even more necessary, in order to the students who get into the higher education might be able to overcome the inserting process difficulties, avoiding, the evasion, the discouragement and promoting significant learning reaches.
\end{abstract}

Keywords: Adults' learning; Higher Education; Insertion; Welcoming at University. 


\section{Introdução}

Uma das questões a serem consideradas nesse trabalho é a configuração da vida adulta nas sociedades contemporâneas, na medida em que a entrada na Universidade para muitos significa também a entrada na vida adulta. Estudos atuais têm demonstrado que a idade adulta, outrora considerada um estágio no qual o sujeito alcançava a maturidade, no qual era capaz de assumir as responsabilidades que a sociedade lhes impunha, hoje é considerada um problema a ser resolvido. (BOUTINET, 1999). A imagem de um adulto pronto e acabado foi se desfazendo e aos poucos, substituída a de um sujeito inacabado em processo de construção.

A sociedade atual oferece desafios constantes que devem ser enfrentados pelos adultos, as incertezas permanentes delineiam a vida adulta. $\mathrm{Na}$ sociedade pós-industrial, o adulto tem encontrado dificuldade para se organizar e organizar sua vida. Boutinet (1999) descreve alguns enfrentamentos do sujeito contemporâneo:

- $\mathrm{O}$ adulto nos limites de si próprio: $\mathrm{O}$ sujeito necessita encontrar respostas e estratégicas para enfrentar situações que são extremas.

- $\mathrm{O}$ adulto em metamorfose cognitiva: o sujeito necessita reordenar suas aprendizagens e é pressionado a tomar decisões e a realizar projetos individuais.

- O adulto mal reconhecido: na cultura pós-moderna o adulto não se sente reconhecido na sua singularidade. Mesmo com os avanços pós-industriais que se voltam para políticas de participação, os adultos passam por desilusões experimentando um sentimento de inutilidade social e pessoal.

- O sujeito à prova de idade: o adulto que envelhece, mas encontra uma sociedade que não aceita o envelhecimento, e por conta disso há uma rejeição da idade.

Em não se podendo mais contar com um padrão de representações do que é ser adulto, como ofereciam as sociedades anteriores, o sujeito atual traça seu próprio caminho, em meio à flexibilidade, incerteza e vulnerabilidade. "[...] Somos realmente levados a ver a vida adulta em termos de itinerário de vida, face às desestabilizações do ambiente, com as quais essa vida adulta precisa se harmonizar sem cessar. [...]" (BOUTINET, 1999, p. 158). Nos contextos atuais, o adulto frente às mudanças pode se disponibilizar a enfrentá-las, contando para isso com recursos pessoais, ou resistir a elas. As mudanças implicam em rupturas em relação às adesões antigas, o que provoca a necessidade de novas adesões. Nessa mesma direção, Bauman (2007) salienta que:

A "vida líquida" e a "modernidade líquida" estão intimamente ligadas. "A vida líquida é uma forma de vida que tende a ser levada adiante numa só sociedade líquido moderna. Líquido moderna é uma sociedade em que as condições sob as quais agem seus membros mudam num tempo mais curto do que aquele necessário para a consolidação, em hábitos e rotinas, das formas de agir. A liquidez da vida e da sociedade se alimentam e se revigoram mutuamente. A vida líquida assim como a sociedade líquido moderna, não pode manter a forma ou permanecer por muito tempo. (BAUMAN, 2007, p. 07).

$\mathrm{O}$ adulto se vê envolto por preocupações tais como: não dar conta dos movimentos constantes, medo de não acompanhá-los, ficar para trás; e por isso, todos correm o tempo todo como se necessitassem livrar-se das coisas, antes mesmo de adquiri-las. Largar o "tudo" sem alcançar o "tudo" passa a ser habitual, o que provoca uma sucessão de reinícios. (BAUMAN, 2007). 
Para Bauman (2007), é neste cenário em transformação, onde tudo se modifica e não há lugar para o apego, onde a vulnerabilidade se torna cada vez mais presente e o consumo se mostra como um dos marcadores de identidade, que o adulto vai traçar seus próprios caminhos buscando construir sua história de vida e sua identidade profissional. Ele percebe que há necessidade de superação dos seus limites para vencer cada dificuldade que apareça. A insegurança do momento faz com que a coragem seja aguçada, como fator propulsor da transposição dos obstáculos.

\section{2. $\mathrm{O}$ adulto e a aprendizagem}

Pensar em como o adulto aprende, nos leva num primeiro momento a buscar um significado para a palavra aprender. Placco e Souza (2006), falam que na procura por esta definição, encontraram em vários dicionários, significados semelhantes e sempre relacionados à aquisição do conhecimento, ao estudo ou implicação.

Claudia Danis (1998), professora agregada ao departamento de psicopedagogia na Universidade de Montreal, diz que são poucas as pesquisas científicas que tratam dos processos de aprendizagem dos adultos, a maioria delas investiga a aprendizagem de crianças e adolescentes. As investigações que têm como tema a aprendizagem de adultos destacam que os adultos não têm a mesma plasticidade para aprender que as crianças, eles selecionam suas aprendizagens e escolhem aprender o que tem sentido para eles. Furlanetto (2010), fala sobre a aprendizagem de adultos, se referindo às diferenças que existem com relação à aprendizagem das crianças:

Os adultos, ao contrário, são portadores de cultura o que os torna mais singulares, críticos e seletivos em relação às novas aprendizagens. Muitas vezes, o novo não acrescenta, mas questiona o que o adulto já sabe, exigindo que transforme suas crenças e idéias. Em tais situações, é necessário desaprender para aprender, o que não se configura tarefa fácil [...] (FURLANETTO, 2010, p. 96).

A afirmação da autora acima citada remete ao pensamento de que a aprendizagem na vida adulta requer disposição da parte do adulto para participar dos movimentos que o levam a aprender.

Placco e Souza (2006) mencionam fatores internos e externos que influenciam a aprendizagem do adulto:

Identificamos fatores e motivos internos que influenciam nossa aprendizagem, como: desejo, interesse, compromisso, necessidade, curiosidade, disciplina, gosto pelo que faz dimensionamento da tensão, preconceito, teimosia, emoções, vínculos, entusiasmo, alegria, euforia e determinação. Reconhecemos também fatores e motivos externos que interferem no processo, como: ajuda mútua, organização e sistematização da situação e do conteúdo, exigência de rigor, diversidades de campo de atuação, amplitude e diversidade exigidas, natureza do conhecimento, desafio permanente, contexto sociopolítico-pedagógico, respeito à diversidade cultural, entre outros, que facilitam e medeiam essa aprendizagem. (PLACCO \& SOUZA, 2006, p.18).

Nota-se nas afirmações de Placco e Souza (2006), que o processo de aprendizagem do adulto é complexo por envolver aspectos variados, que necessitam de interação entre eles. Entende-se que é nesse processo de interação que a aprendizagem ocorrerá. As mesmas autoras falam de quatro aspectos importantes característicos da aprendizagem dos adultos:

- A experiência: como ponto de partida e de chegada da aprendizagem, acredita-se 
que, as experiências anteriores vivenciadas influenciarão as novas aprendizagens;

- O significativo: no processo de aprendizagem de adultos há uma interação de significados cognitivos e afetivos;

- O proposital: que é algo que o adulto precisa alcançar, desenvolver, que o faz se mobilizar para tal;

- A deliberação: a condição que o adulto tem de fazer escolhas com relação a sua própria sua aprendizagem.

Esses aspectos merecem destaque nos processos formativos do adulto, uma vez conhecidos podem ser utilizados para aprimorar tais processos, na tentativa de favorecer o desenvolvimento do adulto.

Nota-se que nos processos formativos, a aprendizagem ocupa um espaço importante e necessário na vida do adulto, na medida em que ela possibilita a construção de novos significados para o enfrentamento das problemáticas relacionadas aos movimentos constantes. Dominicé (2006), afirma que a pluralidade biográfica, a perda de referências culturais e o confronto entre gerações no mundo contemporâneo, fazem com que a formação do adulto esteja focada naquilo que lhe é significativo e relaciona-se com sua própria trajetória de vida.

Para Boutinet (1999), a postura de aprendiz do adulto nasce das necessidades que ele tem de se ajustar às mudanças cotidianas, é por isso que o adulto necessita tornar-se sujeito da sua história, para fazer as escolhas que lhe permitam desenvolver-se. A aprendizagem, nessa perspectiva, é vista como meio para o desenvolvimento profissional e pessoal, ela ocupa um espaço de destaque na atualidade.

\section{Os processos formativos, educação e cultura no Ensino Superior}

Os processos formativos envolvem diversas áreas da vida humana. É possível perceber que há um envolvimento do adulto cada vez maior com a educação, e cada vez mais, o Ensino Superior se torna responsável pela formação de parcelas da sociedade. As exigências do mercado de trabalho (SOARES, 2002) têm contribuído para que isso ocorra.

Segundo Jair Militão da Silva (2011), em seu artigo: "Caminhos para a democratização do acesso, permanência e aprendizagem na universidade", há um ingresso de alunos oriundos de camadas sociais, menos favorecidas no Ensino Superior, esses acesso é alcançado com sacrifícios pessoais, gastos com alimentação transporte, materiais, e mensalidades. Zabalza (2004) também se refere à democratização do acesso no Ensino Superior:

Hoje em dia, a educação superior já não é mais privilégio social para poucas pessoas (normalmente provenientes da classe social média alta), mas que com exceções, se transforma em aspiração plausível para camadas cada vez mais amplas da população. Essa abrangência ocorre não apenas em sentido horizontal (jovens de diferentes classes sociais e de diferentes localizações geográficas), mas também em sentido vertical (indivíduos de diferentes faixasetárias começam ou continuam seus estudos). (ZABALZA, 2004, p.182).

Depreende-se que a educação tem sido um dos meios pelos quais as pessoas acreditam ser possível ascender profissionalmente. Sabe-se, no entanto, que nem sempre isso ocorre, melhor dizendo, o sucesso profissional não depende somente de um curso superior.

No momento em que se encontra a sociedade brasileira, há necessidade de se refletir sobre as questões culturais, econômicas e sociais que chegam ao Ensino Superior por meio das novas camadas que se 
inserem nesse nível de educação. As dificuldades que aparecem em sala de aula podem ser indicadores de questões culturais mais amplas. Silva (2011) fala sobre a cultura:

Cultura pode ser entendida como a maneira de produzir a vida e seus significados. No relacionamento com a natureza, consigo própria e com os demais seres humanos, cada pessoa aprende a melhor maneira de viver em certo ambiente. Esta maneira pode ser considerada a melhor se resiste ao longo do tempo como forma adequada de garantir a vida individual e do grupo em um dado ambiente. (SILVA, 2011, p.40).

$O$ aluno que ingressa no Ensino Superior traz consigo traços culturais, econômicos e sociais que foram construídos em suas vivências e se depara com uma nova realidade que demanda outras competências e comportamentos. Para alguns, a passagem para este nível de ensino pode ocorrer de maneira tranquila, mas, para outros, podem surgir conflitos a serem superados no próprio processo educativo ao longo do curso que o aluno escolheu. Essa superação se faz necessária, caso contrário o aluno não será capaz de usufruir de seu curso encontrando dificuldades para até mesmo finalizá-lo.

\section{A Universidade}

Entende-se a Universidade como um espaço de desenvolvimento humano que se propõe a trabalhar com diversas dimensões da formação profissional. Para Pimenta (2005):

A universidade, enquanto instituição educativa configura-se como serviço público de educação que se efetiva pela docência e investigação tendo por finalidades: a criação, o desenvolvimento, a transmissão e a crítica da ciência, da técnica e da cultura; a preparação para o exercício de atividades profissionais que exijam a aplicação de conhecimentos e métodos científicos e para a criação artística; o apoio científico e técnico ao desenvolvimento cultural, social e econômico das sociedades. (PIMENTA, 2005, p. 40).

Aos objetivos da Universidade integram-se os dos alunos, porém nem sempre esse processo ocorre de forma tranquila. Silva (2011) fala sobre a necessidade de confluência entre os objetivos organizacionais e pessoais. Para o autor, a Universidade, para integrar os alunos, deve trabalhar ou considerar as necessidades reais dos alunos, caso contrário não poderá desenvolver com eles um trabalho pedagógico eficaz.

Zabalza (2004) faz referência a um crescente processo de massificação no Ensino Superior e à concentração de alunos em determinados cursos, o autor fala, também, de algumas questões a serem pensadas com relação ao aumento de alunos na Universidade.

Ao citar a massificação, não nos referimos apenas ao aumento no número de estudantes, já que outras variáveis são atingidas de maneira direta ou indireta pela quantidade de alunos em sala de aula, por exemplo:

- na necessidade de atender a grupos muito grandes;

- na maior heterogeneidade dos grupos;

- na pouca motivação pessoal para estudar;

- na necessidade de contratar novos professores ou de fazê-los iniciar no magistério antes mesmo de estar em condições ideais para isso (estagiários, monitores, pessoal sem experiência docente nem preparação pedagógica);

- no retorno aos modelos clássicos da aula para grupos com muitos alunos 
frente à possibilidade de implementar um procedimento mais individualizado;

- na menor possibilidade de responder às necessidades específicas de cada aluno;

- na menor possibilidade de organizar (planejar e fazer o acompanhamento), em condições favoráveis, os períodos de práticas em contextos profissionais. (ZABALZA, 2004, p.182).

Para Zabalza (2004), a massificação implica no surgimento de alguns empecilhos para introdução de renovações, porque quando as Universidades possuem um número muito grande de alunos, os professores e a Instituição renunciam ao ensino de qualidade. O mesmo autor diz que: Busca-se apenas "sobreviver" e vencer os obstáculos esperando que só os alunos mais capacitados ou mais motivados superem a barreira das primeiras disciplinas, tornando, desse modo, mais suportável a situação nas futuras disciplinas. (ZABALZA, 2004, p.183).

A qualidade no Ensino Superior requer atenção, pois ao mesmo tempo em que se verifica o crescimento desse nível de ensino, percebe-se que surgem situações que necessitam ser repensadas com relação a sua qualidade.

\section{A inserção do aluno na Universidade}

Cumpre destacar mais uma vez, que os alunos que ingressam no Ensino Superior são adultos, este fato aponta para a necessidade de um olhar diferenciado para este nível de ensino. É importante considerar características próprias do aluno adulto, para se pensar em como esses alunos podem enfrentar os desafios no processo de aprendizagem e permanecer na Universidade. Zabalza (2004) salienta:
[...] Podemos dizer com razão, que uma característica fundamental dos estudantes universitários é que são sujeitos adultos, ao menos legalmente, em total posse de sua capacidade de decisão. Dessa condição geral, derivam outras várias que tem grande relevância ao se desenvolver o trabalho da universidade. (ZABALZA, 2004, p. 187).

Ao entrar no Ensino Superior, o aluno carrega suas experiências de aprendizagem que podem favorecer, ou não, sua entrada e permanência. Sua aderência a esse nível de ensino ocorre em meio a situações complexas que articulam suas experiências anteriores ás novas que precisa viver. Coloun (2008) alerta para a importância de se compreender cada vez mais os desafios existenciais enfrentados por aqueles que buscam o Ensino Superior: "Tratase de um ensino que se dirige a adultos e, exatamente por isso, problemas particulares se colocam e deveriam ser estudados [...]". (COLOUN, 2008, p. $33)$.

Coloun salienta, também, que o aluno ao entrar na Universidade precisa aprender seu novo ofício: o de estudante universitário, apesar desse ofício ser provisório e de ter duração de alguns anos.

"A entrada na vida universitária é como uma passagem: é necessário passar do estatuto do aluno ao de estudante". Como toda passagem, ela necessita de uma iniciação[...]. Eu entendo por filiação o método através do qual alguém adquire um status social novo. (COLOUN, 2008, p.32).

É preciso aprender a ser estudante universitário, para que as vivências cotidianas e as exigências da formação em nível superior impulsionem o aluno ingressante. Quando o aluno passa a ser estudante do Ensino Superior, é porque foi reconhecido em suas competências, ele conseguiu legitimar os saberes que adquiriu; mas isso não garante sua permanência que depende de sua adaptação 
às novas condições, caso isso não ocorra, ele corre o risco de fracassar.

Se o fracasso e o abandono são numerosos ao longo do primeiro ano é precisamente porque a adequação entre as exigências acadêmicas, em termos de conteúdos intelectuais, método de exposição do saber, dos conhecimentos e hábitos dos estudantes, que são ainda alunos, não aconteceu (COLOUN, 2008, p.32).

É preciso conhecer os códigos do Ensino superior, é necessário haver um processo de aprendizagem com relação à Instituição, sua cultura e suas rotinas. Coloun (2008) descreve três tempos vivenciados pelo aluno ao ingressar no ensino universitário.

A entrada na universidade pode ser analisada como uma passagem, no sentido etnológico do termo, que eu proponho considerar em três tempos:

1 - O tempo do estranhamento, ao longo do qual o estudante entra em um universo desconhecido, cujas instituições rompem com o mundo familiar que ele acaba de deixar;

2 - O tempo da aprendizagem quando ele se adapta progressivamente e onde uma acomodação se produz;

3 - E por fim, o tempo da filiação que é o do manejo relativo das regras identificado especialmente pela capacidade de interpretá-las ou transgredi-las (COLOUN, 2008, p.32).

Quando Coloun (2008) fala a respeito do tempo do estranhamento refere-se no aluno que ingressa num espaço que para ele é novo, chamado Universidade, e que necessitará de um tempo para assimilar e se dar conta das novas regras que farão parte de sua vida enquanto estiver ali.

O tempo da aprendizagem remete a um processo de familiarização com o novo mundo. Coloun (2008) diz que:
[... Consiste em aprender os rudimentos do ofício: de debutante o estudante se torna aprendiz. Sua angústia inicial será sucedida com a familiarização progressiva com a Instituição, uma adaptação em relação aos códigos locais e pelo início do trabalho intelectual, que devem, em princípio, levá-lo a se tornar um membro competente da comunidade universitária e a ser reconhecido como tal. (COLOUN, 2008, p.151).

A afirmação do autor faz com que se perceba que os caminhos de aprendizagem os quais o aluno universitário tem que percorrer, não são só cognitivos, além desses, existe uma cultura que ele precisa compreender para nela transitar e ser reconhecido.

O tempo da filiação faz com que o estudante se torne um membro do Ensino Superior, ele se estabelece quando o ambiente não é mais hostil, as regras já foram de alguma maneira internalizadas, e o estudante está familiarizado com a vida social e intelectual. Esse tempo faz menção a um aluno que conseguiu se adaptar ao novo mundo no qual se inseriu.

\section{A necessidade de acolhimento}

$\mathrm{O}$ acolhimento do aluno ingressante no espaço universitário é algo que favorece o seu processo de pertencimento, pois uma vez que ele se sinta pertencer à Universidade terá mais facilidade em superar desafios. Silva (2011) diz que:

A identidade de uma pessoa contrói-se pelo seu pertencer concreto a um grupo que comunica uma visão de si e do mundo; é o processo educativo atuando na constituição de seres humanos aptos ou inaptos para a vida democrática. A escola desempenha papel marcante nessa formação (SILVA, 2011, p.42).

Cabe à Universidade, como espaço formativo, propiciar ao aluno um ambiente 
no qual ele possa interagir com os professores, com os colegas e com os conteúdos, para que se torne possível alcançar os objetivos educacionais, tanto da universidade como do aluno.

\section{Considerações finais}

Ao versar sobre alguns aspectos que envolvem a formação acadêmica, considerase que a vida adulta na atualidade é composta por características que lhes são próprias: necessidade de mudanças constantes, capacidade de escolha, tomadas de decisão, responsabilidade pessoal, necessidade de aprendizagem profissional e habilidade para reiniciar em todo tempo.

Nota-se que o aluno que se insere no Ensino Superior traz consigo traços culturais, econômicos e sociais que foram construídos no decorrer de suas trajetórias de vida. Ao se deparar com a Universidade encontra-se com uma nova realidade cultural e social, podendo passar por processos que podem desestabilizá-lo em vários seguimentos.

Ressalta-se a importância do acolhimento por parte da Universidade durante os processos formativos, uma vez que, é nesse espaço que ocorrem os movimentos de aprendizagens e experiências acadêmicas desse aluno adulto. Entende-se que a interação é um dos componentes para a construção das aprendizagens significativas.

A familiarização com a nova realidade é um processo necessário, e que pode apontar caminhos para que o aluno que se insira no Ensino Superior, não desanime, nem desista de concluir o seu curso.

Esse estudo mostra a necessidade de aprofundamento das questões que estão relacionadas às realidades que envolvem o Ensino Superior, no sentido de se buscar estratégias para o acolhimento dos alunos na Universidade. Cada vez mais, a realização de reflexões sobre o ingresso de alunos neste nível de ensino se torna importante e necessária.

\section{Bibliografía}

1. BAUMAN, Z. Vida líquida. Tradução Carlos Alberto de Medeiros. Rio de Janeiro: Jorge Zahar ed.2007.

2. BOUTINET, J. Pierre. A imaturidade da vida adulta. Tradução Dina Osman.PortoPortugal:Rés-Editora Lda,1999.

3. COLOUN, A. A condição de estudante: a entrada na vida universitária; Trad. De: Georgina Gonçalves dos Santos, Sônia Maria da Rocha Sampaio. Salvador: EDUFBA, 2008.

4. DANIS, Claudia. Processos de aprendizagem dos adultos numa perspectiva de desenvolvimento. In: DANIS, C.; SOLAR, C. Aprendizagem e desenvolvimento dos adultos. Tradução Joana Chaves. Les Editions Logiques. Inc.1998.

5. DOMINICÉ, P. A Formação de adultos confrontada pelo imperativo biográfico. Educ. pesqui. vol. 32 n. 2. São Paulo may/aug. 2006.

6. FURLANETTO, E. C. Processos de (trans)formação do professor: diálogos disciplinares. ECCOS- Revista Científica. v.12. n.1, p. 85-101, jan./jun. 2010. 
7. MACHADO, E. V.; SILVA, J. M.; LAUAND, J. (orgs.). As mudanças no mundo do trabalho e a importância da Educação Superior (BASSOTTO, S. A. S. A) In: Filosofia e Educação-Interfaces. São Paulo: Factash - 2011. P.119-128.

8. PIMENTA, S. G.; ANASTASIOU, L. G.

C. Docência do ensino superior. 2. ed. São Paulo: Cortez, 2005.

9. PLACCO, V. M. N. S.; SOUZA, V. L. T. (Orgs.) A aprendizagem do adulto professor. São Paulo: Edições Loyola, 2006.

10. SILVA, J. M. Caminhos para a democratização do acesso, permanência e aprendizagem na universidade. Revista internacional d'umanitats. 23. São Paulo: CEMOrOc-Feusp/Universidade Autònoma de Barcelona, out./dez. 2011, p.39-44. Disponível em:< www.hottopos.com/rih23/ 39-44jair.pdf > . Acesso em 20/02/2012. 11. SOARES, M. S. A. A Educação superior no Brasil. Porto Alegre: 2002.

12. ZABALZA, M. A. O ensino universitário: seu cenário e seus protagonistas. Trad. Ernani Rosa - Porto Alegre: Artmed, 2004. 